-Full Paper-

\title{
Identification of ZAG1, a Novel Protein Expressed in Mouse Preimplantation, and Its Putative Roles in Zygotic Genome Activation
}

\author{
Toshiki MATSUOKA ${ }^{1)}$, Manabu SATO'1), Mikiko TOKORO'), Seung-Wook SHIN1), \\ Atsuto UENOYAMA ${ }^{1)}$, Kazunari ITO'), Syuji HITOMI'), Tomoko AMANO'), Masayuki ANZAI ${ }^{2}$, \\ Hiromi KATO ${ }^{2)}$, Tasuku MITANI ${ }^{2)}$, Kazuhiro SAEKI ${ }^{1,2)}$, Yoshihiko HOSOI ${ }^{1,2)}$, Akira IRITANI ${ }^{1,2)}$ \\ and Kazuya MATSUMOTO ${ }^{1,2)}$
}

\author{
${ }^{1)}$ Division of Biological Science, Graduate School of Biology-Oriented Science and Technology, Kinki University, \\ Wakayama 649-6493, ${ }^{2}$ Institute of Advanced technology, Kinki University, Wakayama 642-0017, Japan
}

\begin{abstract}
We isolated a mouse cDNA, zag1 (zygotic gene activation-associated gene 1), that has an open reading frame of 1,728-bp encoding a protein of $66.2 \mathrm{kDa}$ including both a bipartite nuclear targeting sequence and a P-loop motif containing nucleoside triphosphate hydrolase motifs. Northern blot analysis of mouse tissues showed that zag1 was widely expressed but was especially prominent in the ovary and testis. RT-PCR analysis of in vitro fertilized embryos showed that the abundance of zag1 transcripts in oocytes decreased after fertilization, and zag1 mRNA was detected at $15 \mathrm{~h}$ post insemination (hpi) in fertilized embryos indicating that the gene was expressed at the start of zygotic gene activation at the mouse 1-cell stage. The nuclear-localization of ZAG1 protein in mouse preimplantation embryos at 15 hpi was confirmed by both subcellular analysis of enhanced green fluorescent protein (EGFP)-tagged ZAG1 and immunocytochemical analysis with anti-ZAG1 antibody. Subsequently, using yeast two-hybrid screening, we identified U2 small nuclear ribonucleoprotein B (U2B"), which is associated with pre-mRNA splicing, as a putative interacting partner of ZAG1 protein. Furthermore, knockdown of zag1 expression by an antisense DNA plasmid induced arrest and/or delay of embryonic development in injected 1-cell embryos. These results suggest that ZAG1 may be closely associated with zygotic gene expression in mouse preimplantation embryos.
\end{abstract}

Key words: Embryonic gene activation (EGA), Gene expression, Maternal, Mouse, Preimplantation embryo, Zygotic gene activation (ZGA)

(J. Reprod. Dev. 54: 192-197, 2008)

$\mathbf{T}$ he development of preimplantation embryos is dependent on stored maternal factors in oocytes [1-3]. During meiosis in both male and female germ cells, transcriptional genome activation does not occur. In the mouse, minor zygotic gene activation (ZGA) first occurs during the latter stage of mouse 1-cell embryo development followed by major ZGA during the 2-cell stage [4]. Thus, ZGA depends on transcripts and proteins derived from maternaleffect genes. Several maternal-effect genes have been identified, including Mater [5], Dnmt1o [6], Npm2 [7], Zar1 [8], Oog1 [9, 10], Zfp36l2 [11], Stella [12, 13], Hsf1 [14] and Formin2 [15]. Moreover, transcriptome analyses have revealed that maternal-effect genes are involved in oocyte maturation, maintenenance of meiotic arrest at the MII stage, fertilization and/or early embryonic development [16-19].

The precise regulation of ZGA is considered to be essential for normal development of the preimplantation embryo because appropriate ZGA results in establishment of the totipotency of the fertilized egg and each blastomere of the embryo at the subsequent cleavage stage. However, the molecular mechanisms by which the nuclear reprogramming event at ZGA is regulated remain unclear. Recently, Brg1, a new member of the maternal-effect gene class,

Accepted for publication: February 13, 2008

Published online: March 19, 2008

Correspondence: K. Matsumoto (e-mail: kazum@waka.kindai.ac.jp) was shown to regulate ZGA in the mouse [20].

To understand the molecular basis for regulation of ZGA, we focused on identification and functional characterization of genes activated in the late 1-cell stage of the mouse embryo. In a previous study [21], we obtained cDNAs expressed specifically at minor ZGA by mRNA differential display between oocytes at the MII stage and embryos at the late 1-cell stage. In the present study, we characterized one of these cDNAs, zag1 (zygotic gene activationassociated gene 1). The primary structure of the ZAG1 protein, deduced from the full-length cDNA (1728-bp), is composed of 575 amino acids $(66.2 \mathrm{kDa})$ that include both a bipartite nuclear targeting sequence and P-loop motif containing nucleoside triphosphate hydrolase motifs. Here in, we demonstrate that zag1 may be closely associated with ZGA in early preimplantation development of mouse embryos.

\section{Materials and Methods}

\section{Animals}

All mice (ICR strain) were purchased form Kiwa Experimental Animals (Wakayama, Japan) and maintained in light-controlled, air-conditioned rooms. All animal procedures conformed to the Guidelines of Kinki University for the Care and Use of Laboratory Animals. 


\section{MPYSEVEAKFLGPGKEQTREPCYKKLKSAADDGVSPLRGGPDIH 44}

45 RIQEKPRNNRVAVATINFRRRVCPQEDKTSTDVLKPLHKEMPGDK 89

90 LGGSESIGSPALQDGKPSPLAKDDEIYSTSKAFIGPIYKPPEKKKCR 136 137 ERKSETDTFSSIDSKRRQEEKQKSNSKKLEMDTELSQFYKEIEELE 182 183 NENEASQGSCTEPEPSEEPIISYDWACNTLKSEEENKDLSDVLQS 227

228 HCGYQEYLEDEPDYPCDEQLMPAFCETSFPSFRPEWQSMHPFVI 271 272 PHDPLSSFNYFNFQRFGTPLHPSPDVFHGRDDSQMQNGCYVDS 314 315 YQDGWSCLTFDQNDEYANYDVTSNNVHPFRNGCSVQDESVNNG 357 358 FCEIRECWQDPSMDKHNETDRFVNQWFQEEKLNKLQKLLILLRGL 402 403 PGSGKTTLSRILLGQSRDGIVFSTDDYFHHQDGYRYNVNQLGDAH 447 448 DWNQNRAKQAIDQGRSPVIIDNTNTQAWEMKPYVEMAIGKGYRV 491 492 EFHEPETWWKFDPEELEKRNKHGVSRKKIAQMLDRYEFQMSISIV 536 537 MNSVEPTQKSIQRPLPLEGEQRWGGSLGSHSQVSIADDY 575

Fig. 1. Mouse ZAG1 protein. The deduced amino acid sequence is numbered on the left and right. Abbreviations: Bipartite-NTS; Bipartite nuclear targeting sequence. The sequence data for the ZAG1 protein is available from GenBank ${ }^{\mathrm{TM}}$ under the accession number NP_958757.

\section{Cloning of mouse zag1 cDNA}

A cDNA obtained by mRNA differential display in our previous study [21] was designated zag1. This gene was recently recorded as a mouse cDNA sequence (BC037393) and as a mouse homolog of human phosphonoformate immuno-associated protein 5 (NP_958757), neither of which have identified functions. The amino acid sequence of mouse ZAG1 was deduced (Fig. 1). The open reading frame of mouse zag1 extends 1,728-bp and encodes a protein of 575 amino acids residues with a predicted molecular mass of $66.2 \mathrm{kDa}$. From database analyses (SMART and Bioinformatic Harvester III beta), the ZAG1 protein was suggested to be a soluble protein with a bipartite nuclear targeting sequence [amino acid (aa) 128-139] and a P-loop motif (aa 391-430) as a predicted functional domain. We isolated and cloned the full-length zag1 cDNA by RT-PCR using mRNA extracted and purified from mouse ovaries.

\section{Northern blot analysis}

Total RNA was extracted from nine different mouse tissues by the Trizol/phenol/ chloroform extraction method. Poly(A)+ mRNA was prepared using Oligotex-dT30[super] (Takara, Shiga, Japan) according to the manufacturer's instructions. Two micrograms of mRNA was separated by electrophoresis on a $1 \%$ agarose gel containing formaldehyde and was transferred onto Hybond-N+ nylon membranes (GE Healthcare Bio-Sciences, Piscataway, NJ, USA). The blot was hybridized with a random-primed ${ }^{32} \mathrm{P}$-radiolabelled zag1 cDNA probe (full length) using Express-Hybrid TM buffer (GE Healthcare Bio-Sciences) according to the manufacturer's instructions and was detected using a Bio-Image Analyzer (BAS-2500; Fuji Film, Tokyo, Japan). Three independent experiments were performed to ensure reproducibility.
In vitro fertilization and culture

The procedures for in vitro fertilization were essentially those reported previously [22, 23]. In brief, spermatozoa were collected from the cauda epididymis of a male mouse. The sperm suspension was incubated for $1.5 \mathrm{~h}$ to allow for capacitation at $37 \mathrm{C}$ under $5 \%$ $\mathrm{CO}_{2}$ in air. Oocytes were collected from the excised oviducts of female mice (2-3 months old) that had been superovulated with PMSG followed $48 \mathrm{~h}$ later by treatment with human chorionic gonadotropin (hCG; Puberogen; Sankyo, Tokyo, Japan). Cumulus masses were recovered in pre-equilibrated HTF medium. The sperm suspension was added to the oocyte-containing medium. Morphologically normal fertilized oocytes were collected from the sperm suspension $2 \mathrm{~h}$ post-insemination. The eggs were cultured in KSOM medium [24] at $37 \mathrm{C}$ under $5 \% \mathrm{CO}_{2}$ in air.

\section{Generation of anti-ZAG1 antibody}

For immunization, a peptide (ETDTFSSIDSKRR, residues 141153), which was designed from the deduced amino acid sequence of the ZAG1 considering relative hydrophilicity, was synthesized and purified. Anti-ZAG1 antibody was obtained by injection of this peptide fused to keyhole limpet hemocyanin (KLH) followed by six booster injections at 1-week intervals into New Zealand White rabbits (Kitayama Labes, Kyoto, Japan). The titer of the antiserum was measured by ELISE. Finally, anti-ZAG1 antibody was fractionated with $40 \%$ ammonium sulfate and used in this study.

\section{RT-PCR and Western blot analysis}

The procedures for RT-PCR and Western blot analysis were essentially the same as those reported previously [25]. In brief, in RT-PCR analysis, mRNA were isolated from ten oocytes or embryos. Then, the mRNA were supplemented with Superscript III reverse transcriptase (Invitrogen, Carlsbad, CA, USA) to synthesize first-strand cDNA. A semi-quantitative PCR was carried out using the following primer set for zag1: 5'-GTGGCCACCATTAACTTCAG-3' and 5'-GGGCCTATGAATGCTTTACT-3'. The reaction parameters were one cycle of $94 \mathrm{C}$ for $5 \mathrm{~min}$ and 40 cycles of $94 \mathrm{C}$ for $1 \mathrm{~min}, 55 \mathrm{C}$ for $1 \mathrm{~min}$ and $72 \mathrm{C}$ for $1 \mathrm{~min}$. For the positive control, $g 3 p d h$, was amplified using sense (5'-ACCACAGTCCATGCCATCAC-3') and antisense (5'-TCCACCACCCTGTTGCTGTA-3') primers. Three independent experiments were performed for each. The bands were quantified by densitometry using a Molecular Imager FX (BioRad Laboratories, Hercules, CA, USA). In Western blot analysis, mouse preimplantation embryos were harvested from culture by rinsing with $0.1 \%$ PVA-Phosphate-buffered saline (PBS) dissolved in SDS buffer. The lysates were resolved on 10 or $15 \%$ SDS-PAGE gels and electrophoretically transferred to PVDF membranes (GE Healthcare Bio-Sciences). The membranes were blocked with Block Ace (Dainippon-Pharm, Osaka, Japan) and then incubated with antiZAG1 polyclonal or anti-actin polyclonal (sc-1616; Santa Cruz Biotechnology, Santa Cruz, CA, USA) antibodies in PBS containing $0.2 \%$ Tween 20 , followed by incubation with donkey antirabbit IgG-HRP conjugate (GE Healthcare Bio-Sciences) for antiZAG1 polyclonal antibody or donkey anti-goat IgG-HRP conjugate (GE Healthcare Bio-Sciences). The signal was detected by 
enhanced chemiluminescence (ECL; GE Healthcare Bio-Sciences). Three independent experiments were performed for each antibody.

His-tagged ZAG1 was constructed by subcloning the full-length sequence of zag1 into pQE32. The His-tagged fusion protein was purified on a Ni2+-NTA resin column (Qiagen, Valencia, CA, USA), dialyzed in buffer (20 mM Tris- $\mathrm{HCl}, \mathrm{pH}$ 7.5, $50 \mathrm{mM} \mathrm{NaCl}$, $1 \mathrm{mM}$ EDTA, $10 \%$ glycerol and $5 \mathrm{mM} \mathrm{MgCl}_{2}$ ) and used directly for experiments. The His-tagged zag1 expression vector was used to transform Escherichia coli M15. The fusion protein was purified using a glutathione-Sepharose column (GE Healthcare Bio-Sciences) from the extract of the IPTG-induced transformant. Three independent experiments were performed.

\section{Immunofluorescence staining}

Embryos were fixed in 4\% PFA in PBS (Invitrogen) for $10 \mathrm{~min}$ at room temperature, and then the fixed samples were incubated in PBS containing 0.1-0.2\% Triton X-100 (Nacalai Tesque, Kyoto, Japan) overnight at $4 \mathrm{C}$. The samples were incubated with antiZAG1 polyclonal antibody (1:200) in PBS containing $30 \mathrm{mg} / \mathrm{ml}$ BSA (3\% BSA-PBS) overnight at $4 \mathrm{C}$. After incubation, the samples were reacted with Alexa Fluor 594-labeled donkey anti-rabbit IgG secondary antibody (1:1,000; Invitrogen) for $1 \mathrm{~h}$ at room temperature and then mounted on glass slides in Vectashield mounting medium (Vector Laboratories, Burlingame, CA, USA) containing 2-5 $\mu \mathrm{g} / \mathrm{ml}$ DAPI (Invitrogen). Embryos were observed using a fluorescence microscope for evaluation of each signal. At least three independent experiments were performed.

\section{Microinjection of plasmid DNA vectors}

An expression vector ( $p \beta$-act/zag1-EGFP/SV40) consisting of a fusion gene of zag1 cDNA and enhanced green fluorescence protein (EGFP) under the control of the chicken $\beta$-actin promoter was injected into the pronucleus of 1-cell embryos. After culture, the subcellular localization of the EGFP signal in 2- to 8-cell embryos was detected using a single photon imaging system with a GFP filter.

In order to investigate the effect of knockdown of zag1 on the development of preimplantation embryos, a zag1 antisense vector ( $p \beta$-act/antisense-zag1/IRES/luc+/SV40) with bicistronic expression of zag1 antisense RNA and humanized firefly luciferase was injected into the pronucleus of 1-cell embryos at 8 to $10 \mathrm{hpi}$. Injected embryos showing luciferase activity at $14 \mathrm{~h}$ after injection were selected and cultured to confirm the effect of antisense DNA expression by observation of subsequent development to the blastocyst stage. In these experiments, $p \beta$-act/luc+/SV40 was used as a control expression vector. The results from three experiments were pooled.

\section{Yeast strains and screening of the two-hybrid ovary cDNA library}

The yeast two-hybrid MATCHMAKER LexA system (Takara) was employed to detect specific protein-protein interactions [26]. The mouse zag1 sequence was amplified by PCR and subcloned into the pGilda vector (Takara). A mouse ovary cDNA library in the vector pB42AD was screened. The EGY48 yeast strain used for the screening assay contained both Leu2 and lacZ reporter genes under the control of a LexA-responsive upstream activation site. For the assay, bait and library plasmids were used to simultaneously transform yeast using the lithium acetate procedure. Double transformant cells grown on Ura-, His-, Trp-, Leu- plates were incubated for 5 days at $30 \mathrm{C}$. Positive colonies were picked up and assayed for the lacZ phenotype. Putative positives were picked up and then further tested by assying the colonies for $\beta$ galactosidase activity. Following confirmation of the specificcity of the interaction, ZAG1 binding partners were identified by sequence analysis. The transformation of pGilda-p53 and pB42AD-T antigen were used as negative and positive controls, respectively.

\section{Results}

Mouse zag1 was expressed ubiquitously but was especially abundant in the testis and ovary

The tissue distribution of zag1 gene expression was examined by northern blot analysis of poly(A)+ RNAs from various tissues of adult mice using full-length zag1 cDNA as a probe. Transcripts of approximately $1.8 \mathrm{kbp}$ were detected in all tissues examined, but were detected particularly strongly in the gonad (Fig. 2A). The blots were stripped and reprobed with $\beta$-actin cDNA to ensure equivalent mRNA loading.

Embryonic zag1 transcripts were expressed at minor ZGA in 1cell embryos, whereas ZGA1 protein was constantly detected from the oocyte to at least the 2-cell embryo stage

RT-PCR and Western blot analysis were performed to investigate the developmental profiles of zag1 gene expression in fertilized mouse eggs. Stored zag1 transcripts in unfertilized eggs decreased after fertilization. Zag1 transcript levels increased by approximately four-fold at $15 \mathrm{hpi}$ compared with those at $6 \mathrm{hpi}$ (Fig. 2B and C). These results indicated that embryonic zag1 was expressed as part of the minor ZGA. In Western blot analysis, the anti-ZAG1 antibody recognized a protein of approximately 66.2 $\mathrm{kDa}$, which is the molecular weight predicted for the mouse ZAG1 protein. Western blot analysis of mouse preimplantation embryos at 0, 6, 15 and 24 hpi showed ZAG1 protein was detected constantly, but increased gradually at 15 and 24 hpi (Fig. 2D), indicating embryonic zag1 transcripts expressed in late 1-cell embryos were translated.

\section{Mouse ZAG1 was localized to the nuclei of mouse preimplantation embryos}

We observed the subcellular localization of ZAG1 protein by immunofluorescence in the 1- to 2-cell stage embryos. The nuclei of preimplantation embryos were labeled with DAPI (Fig. 3Ak-o). At the pronuclear stage, ZAG1 protein was localized to the cytoplasm (Fig. 3Af). At the syngamy stage, localization of the ZAG1 protein was observed in around the syngamy (Fig. 3Ag). At anaphase of the first division, ZAG1 protein was localized to between sister chromosomes (Fig. 3Ah). At the early 2-cell stage, we observed the localization of ZAG1 protein around the nuclear membrane (Fig. 3Ai), whereas the localization of ZAG1 protein was observed in the inner nucleus at the late 2-cell stage (Fig. 3Aj). 
A
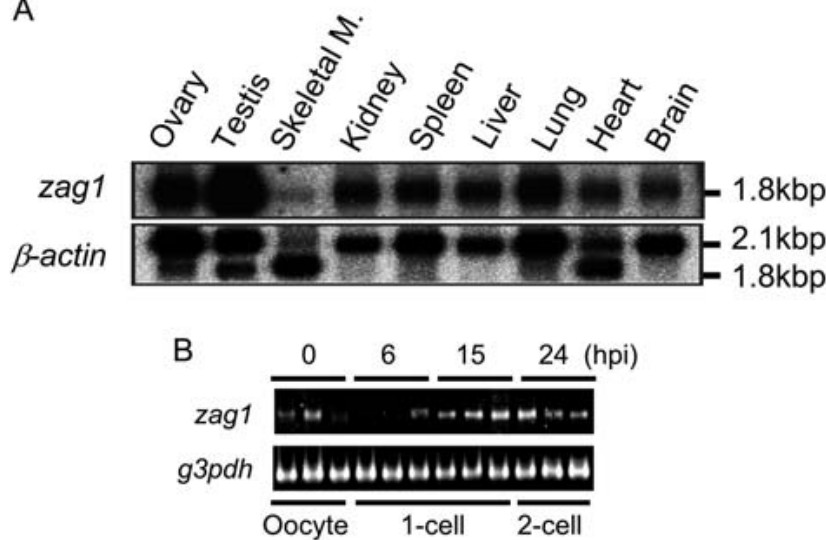

C
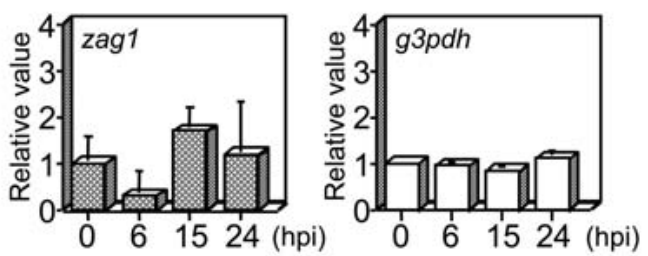

D

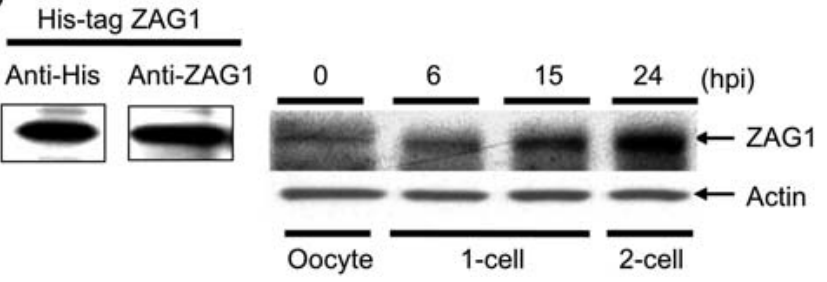

Fig. 2. Expression profile of the zag1 gene during preimplantation development of in vitro fertilized eggs. (A) Northern blot analysis of the zag1 gene in mouse tissues. (B) RT-PCR analysis of zag1 gene expression. (C) Expression profile of zag1 gene in preimplantation embryos. The zag1 gene shows the expression profile of a maternal zygotic gene [15]. (D) Western blot analysis of mouse ZAG1 during early development of in vitro fertilized eggs.

In addition, after microinjection of an expression vector encoding ZAG1-EGFP fusion protein into the male pronucleus of 1-cell embryos, EGFP signals were detected in the nuclei of 2- to 8-cell embryos (Fig. 3B). These results revealed that the previously predicted bipartite nuclear targeting sequence spanning aa 128 to 139 in the ZAG1 protein was confirmed to be functional in the mouse preimplantation embryo.

ZAG1 protein was confirmed to be associating with $U 2 B^{\prime \prime}$ by a yeast two-hybrid system

In order to identify a functional context for ZAG1 in mouse embryos, we performed yeast two-hybrid screens using full-length ZAG1 as the bait and a mouse ovary cDNA library as the prey to identify possible interacting protein partners. Since the zag1 gene was expressed in the mouse oocyte, we used an ovary cDNA library in this study. As a result, U2 small nuclear ribonucleoprotein B (U2B”) was identified as a putative interacting partner for full-length zag1. To identify the specificity of the protein interac-

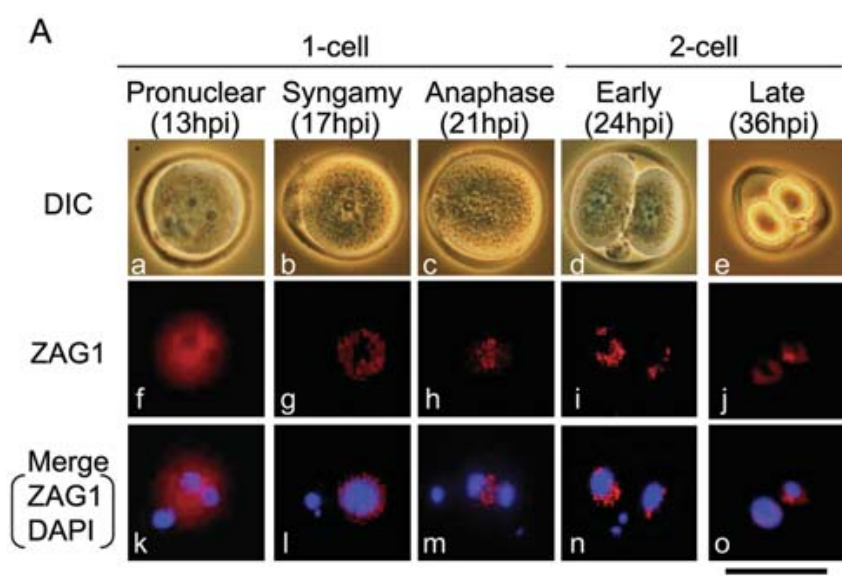

B

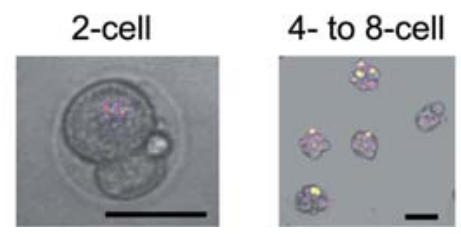

Fig. 3. Subcellular localization of mouse ZAG1 in preimplantation embryos. (A) Differential interference contrast (DIC) (a-e). Mouse preimplantation embryos were immunostained with antiZAG1 polyclonal antibody ( $\mathrm{f}-\mathrm{o})$ and DAPI $(\mathrm{k}-\mathrm{o})$. (B) Subcellular localization of mouse ZAG1-EGFP fusion protein in preimplantation embryos by microinjection of an expression vector encoding ZAG1-EGFP. EGFP signals were detected in the nuclei of 2- to 8-cell embryos. The scale bars are $100 \mu \mathrm{m}$.

tion, pGilda-ZAG1 was co-transformed into yeast with pB42ADU2B” or pB42AD-T antigen. The results showed that ZAG1 gave strong positive signals for interaction with U2B" but not with $\mathrm{T}$ antigen as the negative control (Fig. 4).

Injection of zag1 antisense DNA plasmid induced arrest and/or delay of development of preimplantation embryos

We investigated the effect of knockdown of zag1 expression using an antisense vector ( $p \beta$-act/antisense-zag1/IRES/luc+/SV40) on the development of preimplantation embryos. In this system, which used an antisense vector with internal ribosomal entry sites (IRES), both zag1 antisense RNA and luciferase protein were produced from a message transcribed from the $\beta$-actin promoter (Fig. 5A). After injection of the zag1 antisense vector, 79 (47/60), 3 (2/ $60), 3(2 / 60)$ and $15 \%$ (9/60) of luciferase positive embryos developed to the 1-cell, 2-cell, morula and blastocyst stages, respectively. The developmental rate of luciferase positive 1-cell embryos injected with the zag1 antisense vector to the 2-cell stage was significantly lower compared with that of the control (20 vs. $93 \%, \mathrm{P}<0.05)$. In addition to this cleavage-stage arrest, we observed a developmental delay in luciferase positive 1-cell embryos injected with the zag1 antisense vector compared with that of the control, as shown in Fig. 5. Sixty seven percent (32/48) of luciferase positive 1-cell embryos at 24 hpi developed into 2-cell 

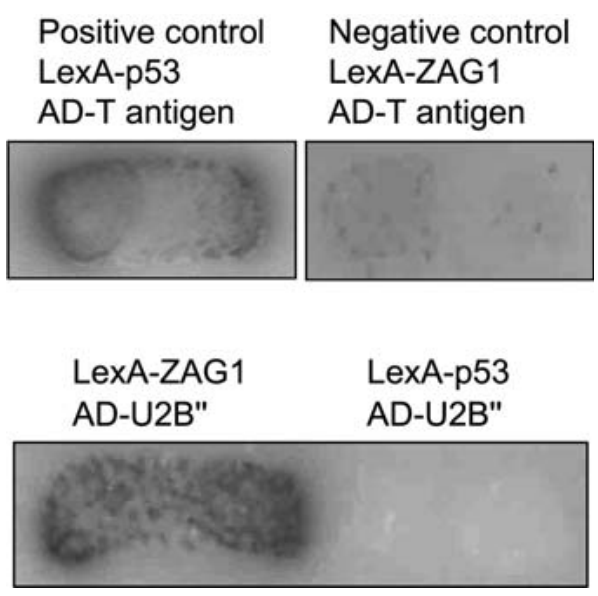

Fig. 4. Identification of a protein that interacts with ZAG1 protein by a yeast two-hybrid system. For the U2B"-binding assays, the full-length ZAG1 was tested for binding using a yeast two-hybrid system.

embryos at $48 \mathrm{hpi}$, and subsequently $81 \%$ (26/32) of injected 2-cell embryos at 48 hpi developed to the 4-cell, 8-cell or morula stages at 72 hpi. By contrast, the luciferase positive 2-cell embryos developed from 1-cell embryos injected with zag1 antisense vector developed to the blastocyst stage at the same rate as the control [69 (9/13) vs $60 \%(18 / 28)$, respectively]. These results showed that zag1 may have some involvement in the development of preimplantation embryos. However, the current findings did not provide definitive evidence of a key role of zag1, and it remains to be determined if a substantial reduction of endogenous zag1 at transcriptional and/or translational levels is induced by expression of antisense RNA.

\section{Discussion}

In this study, we analyzed a functionally unknown gene [renamed as zygotic gene activation-associated gene 1 (zag1) for its speculated function]. The mouse ZAG1 amino acid sequence has a bipartite nuclear targeting sequence and P-loop motif (Fig. 1). The ZAG1 orthologs of rodents and humans have clearly diverged, although conserved sequence stretches are found in the bipartite nuclear targeting sequence and P-loop motif of zag1 proteins. For example, the mouse full-length ZAG1 amino acid sequence shows $87 \%$ identity to that of the rat, whereas the mouse and human proteins share only $65 \%$ identity (data not shown). This species variability of the ZAG1 protein at the structural level could be indicative of relatively rapid evolution in this protein. As shown in Fig. 3A, subcellular localization of ZAG1 protein was observed in the inner nuclei of embryos except for at the mitosis stage. In addition, in mouse 1-cell embryos injected with the ZAG1-EGFP expression vector, subcellular localization of fused ZAG1-EGFP was detected in the nuclei of 2- to 8-cell embryos (Fig. 3B). Taken together, the present study demonstrates that the bipartite nuclear targeting sequence of ZAG1 protein is a functional domain in mouse preimplantation embryos. Furthermore, during our search
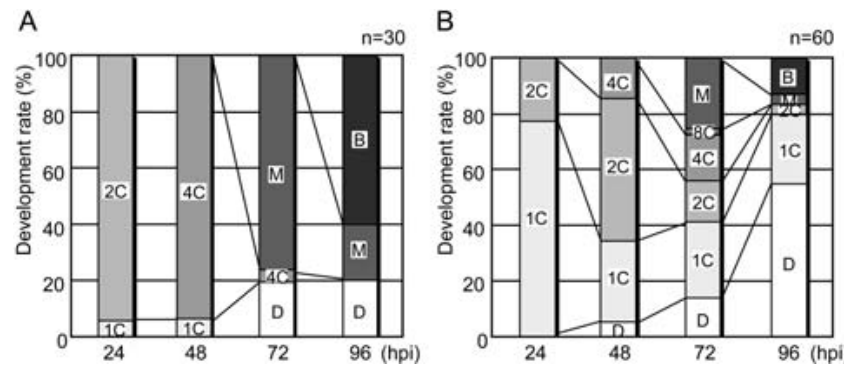

Fig. 5. Injection of a zag1 antisense DNA plasmid induced arrest and/or delay of development of preimplantation embryos (hpi; hour post insemination). (A) Development of preimplantation embryo after microinjection of $\mathrm{p} \beta$-act/luc+/SV40 (positive control). (B) Development of preimplantation embryo after microinjection of $\mathrm{p} \beta$-act/anti-zag1/IRES/luc+/SV40. Degenerated (D;-), 1-cell (1C; $\square$ ), 2-cell (2C; $\square$ ), 4-cell (4C; $\square$ ), 8-cell (8C; $\square$ ), Morula $(\mathrm{M} ; \square)$, Blastocyst (B; $)$.

through databases, we found a P-loop motif in the ZAG1 protein, which is a highly conserved feature of ATP- and GTP-binding proteins that it has been implicated in cleavage of the $\beta$ - $\gamma$-phosphate bond of the NTP [27]. Thus, we speculated that zag1 is involved in DNA replication, chromatin-remodeling, transcriptional regulation, RNA synthesis, RNA processing and RNA transport.

ZAG1 is assumed to play a role in the nucleus of the preimplantation embryo. Using a yeast two-hybrid screen, we showed that U2B" was a binding partner of ZAG1 (Fig. 4), although it is necessary to determine whether U2B" interacts with ZAG1 in vivo by immunoprecipitation analysis using preimplantation embryos. U2B" is a component of $12 \mathrm{~S}$ U2 snRNP complexes in the nucleus [28], which binds hairpin IV of U2 snRNP only when it is complexed with U2A' [29]. U2 snRNPs are involved in prespliceosome assembly and the pre-mRNA splicing mechanisms in the nucleus [30], which is localized from the germinal vesicle to the oocyte cytoplasm and to the pronuclei during ovulation and fertilization [31]. Interestingly, although the central segment of U2B" has an nuclear localization signal (NLS), nuclear import of U2B" does not depend on this NLS [32]. Nuclear import of U2B” has been shown to be important for pre-spliceosome formation [33], which is also a requirement for hydrolysable ATP [34]. Therefore, it is assumed that ZAG1, with its P-loop motif, may be involved in nuclear import of U2B', although it remains to be determined whether the ATP-binding motif of ZAG1 has ATPase activity.

The peptide $\alpha$-amanitin induces suppression of transcription during the minor ZGA phase of the mouse 1-cell embryo [35, 36], but development to the 2-cell stage can still occur by a zygotic clock [37]. Cycloheximide also induces suppression of the minor ZGA during the mouse 1-cell embryo stage [17, 38]. These reports imply that translation of maternal RNA transcripts is necessary for subsequent development of embryos, while embryonic transcripts are not required in late 1-cell embryos. In general, the process of gene expression comprises transcription of RNA, RNA synthesis, RNA processing, mRNA capping, translation of protein, protein synthesis, protein processing and protein modification. However, little is known about the necessity of pre-mRNA splicing in late 1cell embryos. In this study, knockdown of ZAG1, which was 
assumed to be involved in pre-mRNA splicing mechanisms, resulted in arrest and/or delay of development to the 2-cell stage (Fig. 5). Pre-mRNAs, mature mRNAs and proteins originating from maternal and/or embryonic genes likely exist in late 1-cell embryos. Thus, pre-mRNA splicing mechanisms may be important in development of 1-cell to 2-cell embryos. Further investigation is needed to confirm the mechanism of pre-mRNA splicing by the spliceosome in late 1-cell embryos.

In conclusion, our results suggest that zag1 may be a new member of the ZGA regulating genes in the mouse embryo at the late 1cell stage.

\section{Acknowledgments}

We are grateful to Mr. M Hayakumo for technical support. This study was supported by a Grant-in-Aid for the $21^{\text {st }}$ Century COE Program of the Ministry of Education, Culture, Sports, Science and Technology of Japan.

\section{References}

1. Schultz RM. Regulation of zygotic gene activation in the mouse. Bioessays 1993; 15 : 531-538.

2. Latham KM. Mechanisms and control of embryonic genome activation in mammalian embryos. Int Rev Cytol 1999; 193: 71-124.

3. Minami N, Suzuzki T, Tsukamoto S. Zygotic gene activation and maternal factors in mammals. J Reprod Dev 2007; 53: 707-715.

4. Matsumoto K, Anzai M, Nakagata N, Takahashi A, Takahashi Y, Miyata K. Onset of paternal gene activation in early mouse embryos fertilized with transgenic mouse sperm. Mol Reprod Dev 1994; 39: 136-140.

5. Tong ZB, Gold L, Pfeifer KE, Dorward H, Lee E, Bondy CA, Dean J, Nelson LM. Mater, a maternal effect gene required for early embryonic development in mice. Nat Genet 2000; 26: 267-268.

6. Howell CY, Bestor TH, Ding F, Latham KE, Mertineit C, Trasler JM, Chaillet JR. Genomic imprinting disrupted by a maternal effect mutation in the Dnmt1 gene. Cell 2001; 104: 829-838.

7. Burns KH, Viveiros MM, Ren Y, Wang P, DeMayo FJ, Frail DE, Eppig JJ, Matzuk MM. Roles of NPM2 in chromatin and nucleolar organization in oocytes and embryos. Science 2003; 300: 633-636.

8. Wu X, Viveiros MM, Eppig JJ, Bai Y, Fitzpatrick SL, Matzuk MM. Zygote arrest 1 (Zar1) is a novel maternal-effect gene critical for the oocyte-to-embryo transition. Nat Genet 2003; 33: 187-191.

9. Minami N, Aizawa A, Ihara R, Miyamoto M, Ohashi A, Imai H. Oogenesin is a novel mouse protein expressed in oocytes and early cleavage-stage embryos. Bio Reprod 2003; 69: 1736-1742.

10. Tsukamoto S, Ihara R, Aizawa A, Kishida S, Kikuchi A, Imai H, Minami N. Oog1, an oocyte-specific protein, interacts with Ras and Ras-signaling proteins during early embryogenesis. Biochem Biophys Res Commun 2006; 343: 1105-1112.

11. Ramos SB, Stumpo DJ, Kennington EA, Phillips RS, Bock CB, Ribeiro-Neto F, Blackshear PJ. The CCCH tandem zinc-finger protein Zfp3612 is crucial for female fertility and early embryonic development. Development 2004; 131: 4883-4893.

12. Saitou M, Barton SC, Surani MA. A molecular programme for the specification of germ cell fate in mice. Nature 2002; 418: 293-300.

13. Payer B, Saitou M, Barton SC, Thresher R, Dixon JP, Zahn D, Colledge WH, Carlton MB, Nakano T, Surani MA. Stella is a maternal effect gene required for normal early development in mice. Curr Biol 2003; 13: 2110-2117.

14. Christians E, Davis AA, Thomas SD, Benjamin IJ. Maternal effect of Hsf1 on reproductive success. Nature 2000; 407: 693-694.
15. Leder $\mathbf{P}$. The formins: connecting embryonic pattern formation and hypofertility in the mouse. Ann NY Acad Sci 2004; 1038: 75-79.

16. Zeng F, Baldwin DA, Schultz RM. Transcript profiling during preimplantation mouse development. Dev Biol 2004; 272: 483-496.

17. Hamatani T, Carter MG, Sharov AA, Ko MS. Dynamics of global gene expression changes during mouse preimplantation development. Dev Cell 2004; 6: 117-131.

18. Potireddy S, Vassena R, Patel BG, Latham KE. Analysis of polysomal mRNA populations of mouse oocytes and zygotes: dynamic changes in maternal mRNA utilization and function. Dev Biol 2006; 298: 155-166.

19. Su YQ, Sugiura K, Woo Y, Wigglesworth K, Kamdar S, Affourtit J, Eppiq JJ. Selective degradation of transcripts during meiotic maturation of mouse oocytes. Dev Biol 2007; 302: 104-117.

20. Bultman SJ, Gebuhr TC, Pan H, Svoboda P, Schultz RM, Magnuson T. Maternal BRG1 regulates zygotic genome activation in the mouse. Genes Dev 2006; 20: 1744 1754.

21. Matsumoto K, Nakagami K, Otake S, Tanaka H, Hashimoto Y, Yamada S, Saeki K, Hosoi $Y$, Iritani A. Identification of genes expressed in mouse unfertilized and fertilized eggs using differential display of RNA. J Fertil Implant 2001; 18: 5-7.

22. Mizuno S, Sono Y, Matsuoka T, Matsumoto K, Saeki K, Hosoi Y, Fukuda A, Morimoto Y, Iritani A. Expression and subcellular localization of GSE protein in germ cells and preimplantation embryos. J Reprod Dev 2006; 52: 429-438.

23. Anzai M, Nishiwaki M, Yanagi M, Nakashima T, Kaneko T, Taguchi $Y$, Tokoro $M$ Shin SW, Mitani T, Kato H, Matsumoto K, Nakagata N, Iritani A. Application of laser-assisted zona drilling to in vitro fertilization of cryopreserved mouse oocytes with spermatozoa from a subfertile transgenic mouse. J Reprod Dev 2006; 52: 601-606.

24. Ho Y, Wigglesworth K, Eppig JJ, Schultz RM. Preimplantation development of mouse embryos in KSOM: augmentation by amino acids and analysis of gene expression. Mol Reprod Dev 1995; 41: 232-238.

25. Matsumoto K, Nakayama T, Sakai H, Tanemura K, Osuga H, Sato E, Ikeda JE. Neuronal apoptosis inhibitory protein (NAIP) may enhance the survival of granulose cells thus indirectly affecting oocyte survival. Mol Reprod Dev 1999; 54: 103-111.

26. Estojak J, Brent R, Golemis EA. Correlation of two-hybrid affinity data with in vitro measurements. Mol Cell Biol 1995; 15: 5820-5829.

27. Smith CA, Rayment I. Active site comparisons highlight structural similarities between myosin and other P-loop proteins. Biophys J 1996; 70: 1590-1602.

28. Behrens SE, Tyc K, Kastner B, Reichelt J, Luhrmann R. Small nuclear ribonucleoprotein (RNP) U2 contains numerous additional proteins and has a bipartite RNP structure under splicing conditions. Mol Cell Biol 1993; 13: 307-319.

29. Scherly D, Boelens W, Dathan NA, Van Venrooij WJ, Mattaj IW. Major determinants of the specificity of interaction between small nuclear ribonucleoproteins U1A and U2B" and their cognate RNAs. Nature 1990; 345: 502-506.

30. Caspary F, Shevchenko A, Wilm M, Seraphin B. Partial purification of the yeast U2 snRNP reveals a novel yeast pre-mRNA splicing factor required for pre-spliceosome assembly. EMBO J 1999; 18: 3463-3474

31. Dean WL, Seufert AC, Schultz GA, Prather RS, Simerly C, Schatten G, Pilch DR, Marzluff WF. The small nuclear RNAs for pre-mRNA splicing are coordinately regulated during oocyte maturation and early embryogenesis in the mouse. Development 1989; 106: 325-334.

32. Kambach C, Mattaj IW. Nuclear transport of the U2 snRNP-specific U2B" protein is mediated by both direct and indirect signaling mechanisms. J Cell Sci 1994; 107: 18071816.

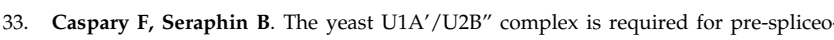
some formation. EMBO J 1998; 17: 6348-6358.

34. Hetzer M, Mattaj IW. An ATP-dependent, Ran-independent mechanism for nuclear import of the U1A and U2B" spliceosome proteins. J Cell Biol 2000; 148: 293-303.

35. Kidder GM, Green AF, McLachlin JR. On the use of $\alpha$-amanitin as a transcriptional blocking agent in mouse embryos: a cautionary note. J Exp Zool 1985; 233: 155-159.

36. Warner CM, Hearn TF. The effect of $\alpha$-amanitin on nucleic acid synthesis in preimplantation mouse embryos. Differentiation 1977; 7: 89-97.

37. Wiekowski M, Miranda M, DePamphilis ML. Regulation of gene expression in preimplantation mouse embryos: effects of the zygotic clock and the first mitosis on promoter and enhancer activities. Dev Biol 1991; 147: 403-414.

38. Wang Q, Latham KE. Requirement for protein synthesis during embryonic genome activation in mice. Mol Reprod Dev 1997; 47: 265-270. 